\title{
Operando In-Situ Microstructure and Structure Studies of Transformations in Advanced Materials
}

\author{
Andrew J. Allen ${ }^{1}$, Fan Zhang ${ }^{1}$, Lyle E. Levine ${ }^{1}$ and Jan Ilavsky ${ }^{2}$

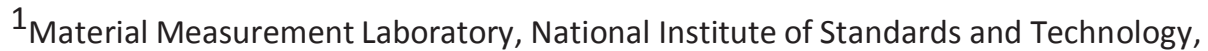 \\ 100 Bureau Dr., Gaithersburg, MD 20899, USA \\ ${ }^{2}$ X-ray Science Division, Argonne National Laboratory, 9700 S. Cass Ave., Argonne, IL 60439, USA
}

Several recent studies by the authors have highlighted the importance of using crystallographic methods to measure \& quantify transformation processes in advanced materials under operando in situ conditions [1-3]. Each study has provided insights concerning a process of technological importance, not tractable either by ex situ crystallographic measurements or by noncrystallographic methods even if carried out under operating conditions. These studies have become possible following major upgrades of the ultra-small-angle X-ray scattering (USAXS) facility at the Advanced Photon Source (APS), Argonne National Laboratory, IL [1]. Four major developments have transformed the APS USAXS facility. These comprise a conversion to higherorder Bonse-Hart crystal optics and consequently higher X-ray energies as the standard operating mode, the introduction of rapid fly-scan measurements in place of previous step- scanning, automated contiguous pinhole small-angle X-ray scattering (SAXS) measurements (using a 2D detector) at intermediate $q$ (where $q=(4 \pi / \lambda) \sin \theta, \lambda$ is the X-ray wavelength, and $\theta$ is one half of the scattering angle), and further contiguous wide-angle X-ray scattering (WAXS) measurements (using a second 2D detector) for X-ray diffraction (XRD) without disturbing sample geometry. With each measurement mode using the USAXS incident beam optics upstream of the sample, USAXS/SAXS/WAXS measurements are now made in $\approx 5$ minutes, allowing operando in situ measurement capabilities of great flexibility under a wide range of sample conditions.

Important examples highlighting the new capabilities include the following. Operando in situ USAXS/SAXS/WAXS studies of an additive-manufactured nickel-based superalloy have quantified the emergence $\&$ evolution of a deleterious $\delta$-phase that emerges in post-build heat treatments designed to relieve residual stresses resulting from the AM build process [2]. With d-phase associated with solute microsegregation in the AM build process, itself, our operando in situ studies have quantified how it can be eradicated by a further homogenization heat treatment. Other operando in situ studies have quantified the transformation of PVP-coated silver nanoparticles (AgNPs) to $\mathrm{Ag}_{2} \mathrm{~S}$ in an aqueous environment, in the presence of natural organic matter (NOM), specifically, in moderately reduced hard water with fluvic acid and dissolved $\mathrm{Na} 2 \mathrm{~S}$ [3]. The surprisingly stable first-order sulfidation reaction without $\mathrm{AgNP}$ aggregation, the crystalline transformation of $\mathrm{Ag}$ to $\mathrm{Ag} 2 \mathrm{~S}$ from the outside inwards, and the absence of detectable Ag ions in solution, all have profound implications for the impact of ongoing widespread releases of AgNPs into the environment. Finally, we have developed operando in situ USAXS/SAXS/WAXS studies of selective gas adsorption in metal-organic framework (MOF) sorbent systems during adsorption/desorption of $\mathrm{CO}_{2}$ and $\mathrm{CO}_{2}$ gas mixtures under realistic pressure conditions [4]. With such data (see Fig. 1.), we seek new insights to connect features in the isotherm curves with underlying changes in sorbent microstructure or structure, relevant to technologies for carbon mitigation \& enhanced gas recovery.

This paper will summarize the new USAXS/SAXS/WAXS capabilities and use these examples to illustrate the power of the new capabilities in operando in situ applications.

[1] J. Ilavsky et al., J. Appl. Cryst., submitted (2018). [2] F. Zhang et al., Acta Mater., submitted (2018). [3] F. Zhang et al., ACS Nano, submitted (2018). [4] A.J. Allen et al., J. Alloys and Compounds, 647, 24-34 (2015).

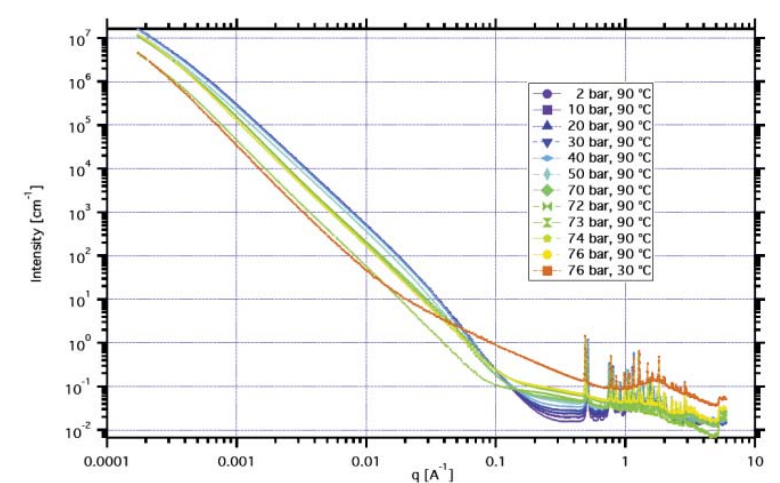

Figure 1. Combined USAXS/SAXS/WAXS data measured under operando in situ conditions for MOF undergoing $\mathrm{CO}_{2}$ adsorption extending into the supercritical $\mathrm{CO}_{2}$ regime. 